\title{
Taking the Qingdao Binhai University Museum of Art as an Example to Discuss the Design of Tourist Souvenirs
}

\author{
Jian Zhao ${ }^{1, ~ a, ~ L i a n g ~ Z h a n g ~}{ }^{1, b}$ and Linan Zheng ${ }^{1, c}$ \\ ${ }^{1}$ Mechanical and electrical Engineering college,Qingdao Binhai University,Shandong, China

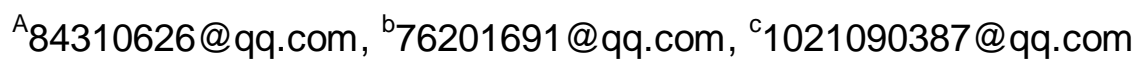

\section{Keywords: Souvenir; Art Museum; Product design; Practicability}

\begin{abstract}
Tourism has become a major modern people's entertainment and leisure projects, various kinds of art galleries, museums are the best choice for people to travel. Through the survey, it found that most of the products are lack of new ideas, no practical value in current tourism souvenir industry in our country.Different places and different attractions souvenirs are stereotyped, which can not reflect the characteristics of tourism[1].Therefore, from the point of view of design innovation, combined with the analysis of tourists and purchasing power of the investigation,we design and research the modeling of the Museum of Art Museum of Qingdao Binhai University.Through the study of the Art Museum of Qingdao Binhai University we have a profound understanding, According to the characteristics of the Art Museum of Qingdao Binhai University and the analysis of the visitors, we Study and design souvenirs which have the characteristics of the Art Museum of Qingdao Binhai University.It reflects the characteristics of Qingdao Binhai College Museum of Art, and enhances the influence of Qingdao Binhai University.
\end{abstract}

\section{Introduction}

Museum of Art is a cultural symbol, and is more rich, deep, elegant and fun. In relation to other tourist attractions, Museum of Art has a unique cultural taste, deep historical connotation and unique personality traits.It is a way of tourism which combies tourism and cultural influence, and meets the growing spiritual and cultural needs of urban and rural residents[2].It will play an irreplaceable important role,in improving the ideological and moral and scientific and cultural quality of the whole nation, developing and prosperiting socialist advanced culture, building a socialist harmonious society. Binhai College Museum of Art as a national 4A scenic which spot of "collection, research and education," three basic functions take the direction of development and construction as the future work. Its long-term goal is to build a national vision, including a variety of disciplines, services in the University, serving the community, which has a strong strength and a greater impact on the characteristics of a comprehensive university art museum.

\section{Development History of Qingdao Binhai University Museum of Art}

Qingdao Binhai College Museum of Art was founded in June 2004, formerly known as Qingdao Binhai College Museum. In order to highlight the museum's features and fully reflect the functions of its teaching, scientific research, Qingdao Binhai College Museum was renamed the Museum of stuffed animals in the world in 2013. The museum is a collection of geological specimens, paintings, ceramics, carving and other collections in an integrated art gallery, covering an area of 14,000 square meters. To highlight the positive artistic tension S-shaped smooth curve shape, the external environment Nagareizumi Diepu shade trees; internal and foreign collections Concurrently, ancient and modern, and build. Since the hall, it has served as a cultural and social hall for the whole school open primary and secondary schools. The museum more than a decade, pupils and students received more than 300 million people, while in science education, effectively promote the school to promote natural science education and environmental ethics education. In November 2012, the museum was awarded the "excellent science base Huangdao honorary title of" Qingdao (Zone) Science and Technology Association and Qingdao Development Zone Finance Bureau; In April 2013, was awarded the 
"three-star science base in Shandong Province," the title of Shandong Province Science and Technology Association and the provincial Department of Finance; In November 2013, the Qingdao Municipal Bureau of Tourism, "national AAA level scenic spots"; In February 2014, the Qingdao Municipal Finance Bureau, the Municipal Forestry Bureau and the Municipal Association for Science "Qingdao ecological science education base"; In May 2015, was awarded the "Shandong Province star science base" title Shandong Province Science and Technology Association and the provincial Department of Finance; In May 2015 by the Chinese Association for Science and Technology awarded "2015--2019 annual national science education base," the title; In December 2015, it was named the Shandong Provincial Tourism Bureau as "national 4A level scenic spots."

\section{Study on the Classification Design of Museum of Art}

In the 21st century rapid socio-economic development, people growing GDP, growing proportion of consumer entertainment, including tourism become an important recreational project. Annual holiday visitors from various tourist attractions, and tourist souvenirs purchasing power continues to rise. However, China Art Gallery souvenir lack of innovation in design development, souvenirs become the soft underbelly of the development of the Museum of Art. With Coast Museum of Art, for example, we are all on display hawking art gallery exhibits some of the printed T-shirts, hats, and other small ornaments, traditional formality, the lack of unique and innovative, missing art gallery features. Museum of Art and souvenirs can represent is very scarce [3].Through the study of Qingdao Binhai College Museum of Art has a deep understanding of the research based on an analysis of Qingdao Binhai College Museum of Art features and visiting populations, study design with Qingdao Binhai University Art Museum souvenirs. Which reflects the characteristics of Qingdao Binhai College Museum of Art, the Museum of Art enhances Qingdao Binhai University influence.

Class Furnishings with Useful Features Memorabilia. With the changes in people's income and consumption concept, souvenirs become a bridge of cultural exchange, a good souvenir to have distinctive features not only, but also have its uniqueness. Therefore, the coastal galleries display art gallery representative class souvenirs positioned scenery as the theme, designed with Qingdao Binhai College Museum of Art and cultural connotation characteristic taste of souvenirs. Men and women who come to visit the Museum of Art, how to design attractive souvenirs is also an important issue. Museum of memorabilia not only has cultural characteristics of temperament, but also have fashion features. After investigation and analysis, Qingdao Binhai College Museum of Art crowds of tourists are mainly schoolchildren based. Weekend tours who visit the collective animal specimens' museum, are the children who are accompanied by their parents or science education under the leadership of the teacher [4].Therefore, the innovative design of souvenirs should be mainly students, and design a playful children and meets aesthetic furnishings category souvenirs. Considered in the design of the furnishings and memorabilia class combination of school supplies, not only to meet the needs of children, but adults, the elderly, too, we can put it on the desk. Art Gallery furnishings category souvenirs not only represents the characteristics of the Museum of Art, and stylish appearance, usability strong, is no longer a simple decoration.

Qingdao Binhai University Museum of Art 's visitors subject is students, relatively few adults. Age less tourists tending to playful, their imagination is more abundant. Therefore, coastal galleries furnishings category souvenirs which will be based on the principles of bio mimicry design abstract animal shapes. The abstract design abstract concrete object type changes, making it consistent with the design of the product shape. Abstract design souvenirs vivid, are able to attract the eyes of tourists. Bionic design modeled on a plant or animal body, on the basis of its abstract, it's ergonomic design principles[5].Bionic design biological body will not be directly applied to the design, but to seize the "spirit" of the principle of good grasp of contemporary aesthetic trends, product modeling in line with modern society, people's aesthetic. Such as deer and peacocks shape, making it interesting, I believe the more popular children's favorite. In terms of functionality combined with school supplies, a greater 
degree of compliance with the primary school children, with LED lighting set, wood grain pattern modification, not only simple and beautiful shape, there are certain practical value.

Adorable Stationery Souvenirs. Stationery as people's daily life necessities, with its practical, easy to carry, and other advantages becomes people's favorite. Previously due to economic development, stationery mostly just used for writing, style monotonous and corny. However, with the improvement of people's living standards, people began to pursue the new personality of stationery, which shows their own tastes and preferences. Therefore, the development of stationery industry is rapid, in order to meet the needs of the public. With the gradual development of stationery gradually become a kind of art, a good designer to design stationery which can even be called a work of art, for everyone to enjoy and collection[6]. According to the analysis of the market survey as well as the tourist crowds, Qingdao Binhai University Museum of Art's visitors who's distribution mainly concentrated in 5-35 years old, the youth is the main body of the visitors, especially the largest number of primary and middle school students in this stage. In addition, the survey found that the art museum visitors are the primary and secondary school students in the parents or teachers, accompanied by popular science education. Stationery and the Art Museum of Qingdao Binhai University features is a combination of design, production and sales of commemorative stationery, there will be a very good market prospects.

Expensive stationery is generally used to treasure the collection. The production of exquisite stationery will be a combination of local features and stationery. People who buy them are also in order to make this a good collection. The object which used this kind of expensive stationery is usually a collection of souvenirs. Second, some of the stationery with practical value, the price is relatively cheap and easy to buy. the design is usually innovative, which can highlight the personality and appearance, easy to use and practical [7]. Usually adults buy them for children, because children curiosity, love of interesting things fresh, which can give stationery to make them happy and make them interested in learning, make writing become fun. For example, during the Games in our country, as a mascot Fuwa it has held depth of people's favorite. Many of its related souvenirs came into being, including the image of the mascot of the pencil and black gel pen is the loveliest. Such a lovely stationery souvenirs gave elementary and junior high school students will make them feel happy, is practical, too, can inspire them to write like, then can encourage them to write the word, to the timely completion of work; Relative to the type of stationery memorabilia collection, its function is in doubt after combining some specialty design, last foothold or practical.

According to the cultural connotation Qingdao Binhai College Museum of Art, as well as for the needs of the market get several ideas. Ruler take elephant specimens in Museum of Art as the prototypeJoin people for basic impression is that elephants long nose, the nose becomes elongated ruler, the image is more lovely and moving. Scissors's prototype is hippo specimens in the Museum of Art. Hippopotamus large nostrils can put a finger, whose image processing has been exaggerated, and the hippo designed as a pair of scissors. Giraffe ballpoint pen also takes advantage of the characteristics of long neck giraffe. Bear pencil sharpener main take advantage of the Museum of Art Great Pyrenees who complete round shape, and more stable. Pay attention to the cultivation of children's thinking ability, develop thinking, enhance the ability of operation skills and hand eye coordination.

Puzzle-type Toys Souvenirs. Toys are the process by which adolescents interact to produce human-machine effect, whose main function is entertainment for children in the process to improve intelligence and increase creativity. Children playing with toys is also reflected which is the value of toys. A good toy product is not only functional, but also more important is the impact of this product and interact with the children at the same time [8]. This effect is positive, lasting, and controllable. Children's toys design, from the shape of speaking, should be rounded to the whole, and reflect a kind of affinity. Furthermore, lovely can meet the psychological needs of adolescents. Simple and clear and lovely shape is the trend of contemporary toys. Simple modeling can facilitate young people's memory, lovely shape, but also attract young people. So that children play together will experience happiness, enjoy the joy of the heart. According to the study of human color psychology, $98 \%$ of the children like 
bright bright colors of toys [9].Color is one of the most direct ways to convey information, and is the product of the clothes. Which can quickly, vividly and correctly convey the information of the goods? Products due to color become more dynamic, good color match can not only enhance product quality, but also condensed into a culture. Youth of bright color has a unique sensitivity investigation power, so the color scheme of children's educational toys should be bright and bright. Materials are also very important, the color is the first visual information, and give people the second kinds of tactile sensation. For toy souvenirs design, texture is also related to the role of the protection of young people, which choose a good toy material, the common material has plastic materials, wood, cloth, etc.

Digital Souvenir. According to the investigation and the current market souvenirs sales reflected, the future of souvenir design is the main direction of digital. Good souvenirs are in line with the requirements of people's life, consumer psychology, consumption levels, green environmental protection. On the one hand, you can always save it. When you see the beautiful souvenirs, you can think of the local scenery, and remember the wonderful journey. Souvenir for a friend, the friend can also experience the local specialties by souvenir. On the other hand, giving friends a souvenir, not only shows the respect for friends, but also quietly plays a role in the promotion of attractions, which become the main reason to attract more tourists. Take the Museum of Shaanxi Province as an example, which is the large exhibition hall of Beijing's the Imperial Palace Museum, it's souvenirs are very different, which use a digital projection. The price is not high, and the cost is not high, but the effect is excellent, which is mainly a small portable projector. Museum of comparative characteristics of the exhibits are recorded by digital scanning way, which put into a small projector. When people want to watch later ,need to open the projector at any time, then you can see the three-dimensional museum exhibits[10].This digital technology derived from the Mogao Grottoes in Dunhuang, which is the most advanced modern way of recording, This kind of digital technology not only has no pollution, environmental protection, but also its most important piont is that which is able to lower the cost of mass production and reuse, high efficiency using, meet the needs of the vast majority of tourism. This digital souvenir will become the development trend of Museum of art in future.

\section{Conclusion}

The design of the Museum of art should follow the characteristics of its venues and the characteristics of the visitors. Corresponding consumption levels and consumer characteristics of demand research, souvenirs are designed to meet the needs of the visitors, practical needs, aesthetic needs and trend of souvenirs in future.

\section{References}

[1] Dawson Munjeri. Tangible and Intangible Heritage: From Difference t o Convergence [J]. Museum International, 2004,56(1).

[2] Shuming Liang. Chinese Culture [M]. Shanghai Century Publishing Group, People's Publishing House, 2012.3.(In Chinese)

[3] Qiu Weili.Tourism souvenir design in the traditional sense of local cultural elements [J]. packaging engineering, 2012.10.(In Chinese)

[4] Fuguang Zhang, Wang Guang.souvenirs emotional interaction design aesthetics technology research [ J ]Aesthetics Technology,2013(In Chinese)

[5] Christian M.Rogerson.Conference and Exhibition Tourism in the Developing World:The South African Experience[J].Urban Forum,2005,9

[6] Xingyi Bai.Tourism souvenir design based on regional culture connotation[J]. China Packaging,2012.05.33 (20):109-112(In Chinese) 
[7] Song Xinping.Research on the development of Museum products based on experience[J].Northern economy.2011, 20:55 -58(In Chinese)

[8] M Gray. Geodiversity: The origin and evolution of a paradigm. Geological Society, London, Special Publications, 2008, 300: 31-36.

[9] A C Mathis. Communicating geoheritage values with the public. 2005 Salt Lake City Annual Meeting of GSA/Geological Society of America Abstracts with Programs, 2005, 37(7):190.

[10] LuMengmeng.Research on the development of creative cultural products in Museum [M]. Nanjing Arts Institute, 2012. 